\title{
Improved sugar co-utilisation by encapsulation of a recombinant Saccharomyces cerevisiae strain in alginate-chitosan capsules
}

\author{
Johan O Westman ${ }^{1,2}$, Nicklas Bonander ${ }^{2}$, Mohammad J Taherzadeh ${ }^{1}$ and Carl Johan Franzén ${ }^{2 *}$
}

\begin{abstract}
Background: Two major hurdles for successful production of second-generation bioethanol are the presence of inhibitory compounds in lignocellulosic media, and the fact that Saccharomyces cerevisiae cannot naturally utilise pentoses. There are recombinant yeast strains that address both of these issues, but co-utilisation of glucose and xylose is still an issue that needs to be resolved. A non-recombinant way to increase yeast tolerance to hydrolysates is by encapsulation of the yeast. This can be explained by concentration gradients occuring in the cell pellet inside the capsule. In the current study, we hypothesised that encapsulation might also lead to improved simultaneous utilisation of hexoses and pentoses because of such sugar concentration gradients.
\end{abstract}

Results: In silico simulations of encapsulated yeast showed that the presence of concentration gradients of inhibitors can explain the improved inhibitor tolerance of encapsulated yeast. Simulations also showed pronounced concentration gradients of sugars, which resulted in simultaneous xylose and glucose consumption and a steady state xylose consumption rate up to 220-fold higher than that found in suspension culture. To validate the results experimentally, a xylose-utilising S. cerevisiae strain, CEN.PK XXX, was constructed and encapsulated in semi-permeable alginate-chitosan liquid core gel capsules. In defined media, encapsulation not only increased the tolerance of the yeast to inhibitors, but also promoted simultaneous utilisation of glucose and xylose. Encapsulation of the yeast resulted in consumption of at least $50 \%$ more xylose compared with suspended cells over 96-hour fermentations in medium containing both sugars. The higher consumption of xylose led to final ethanol titres that were approximately $15 \%$ higher. In an inhibitory dilute acid spruce hydrolysate, freely suspended yeast cells consumed the sugars in a sequential manner after a long lag phase, whereas no lag phase was observed for the encapsulated yeast, and glucose, mannose, galactose and xylose were utilised in parallel from the beginning of the cultivation.

Conclusions: Encapsulation of xylose-fermenting S. cerevisiae leads to improved simultaneous and efficient utilisation of several sugars, which are utilised sequentially by suspended cells. The greatest improvement is obtained in inhibitory media. These findings show that encapsulation is a promising option for production of second-generation bioethanol.

\footnotetext{
* Correspondence: franzen@chalmers.se

${ }^{2}$ Chemical and Biological Engineering, Industrial biotechnology, Chalmers

University of Technology, 41296 Göteborg, Sweden

Full list of author information is available at the end of the article
} 


\section{Background}

Second-generation bioethanol has long been suggested as a contender to become the main type of renewable liquid fuel [1]. Nevertheless, there are issues with its production that still limit its commercialisation. One of the main problems is the issue of inhibitors produced during the pretreatment and hydrolysis of the raw material into fermentable sugars. Another problem is the fact that pentoses are not fermentable by wild-type Saccharomyces cerevisiae [2], although there are a few exceptional cases of slow consumption [3]. The most popular approach to this problem has been to create recombinant strains of $S$. cerevisiae utilising xylose, arabinose or a mixture of the two [4]. However, these strains still have the problem of poor simultaneous co-utilisation of the pentoses together with hexoses [5]. Xylose will not be consumed in considerable amounts until the concentration of glucose is low [6,7]. The reason for this is that there are no specific pentose transporters in $S$. cerevisiae, and pentoses are instead transported by the native hexose transporters $[8,9]$. However, these transporters have higher affinity for glucose, and therefore there is a strong preference for glucose uptake as long as it is present.

Cell retention through immobilization of the cells can be used as a means to increase the volumetric productivity of biological processes [10]. Numerous examples of immobilization of various microbial cells in alginate beads can be found in the literature, for example, the immobilization of Debaryomyces hansenii for xylitol production [11,12] or of $S$. cerevisiae for ethanol production [13]. Immobilization produces several benefits to the process, such as easier cell reuse at high biomass concentration. Cell encapsulation in a semi-permeable membrane differs from bead immobilization in that the cells grow inside a liquid core, forming a dense cell pellet inside the capsule rather than being dispersed in the pores of the alginate matrix [10]. Encapsulation appears to be a good solution to the first of the aforementioned problems, the inhibitor tolerance. It has been shown that encapsulation of the yeast increases its tolerance towards convertible inhibitors such as the furan aldehydes. This effect is believed to be a result of concentration gradients, which are formed when cells close to the membrane convert inhibitors; the cells closer to the core of the pellet are then surrounded by sub-inhibitory levels of the inhibitors, and can still ferment the medium efficiently [14]. It has also been shown on a proteomic level that there are cells in the capsule that are starved despite the presence of high 'extracapsular' levels of glucose [15]. This is most likely an effect of concentration gradients of glucose occurring throughout the cell pellet inside the capsules, owing to consumption of glucose by the yeast cells and limitations in mass transfer. Such concentration gradients could hypothetically also promote glucose and xylose co-utilisation. Inside a capsule, some cells will experience a low glucose concentration at the same time that other cells experience a high glucose concentration; however, because glucose inhibits xylose consumption all cells may experience relatively high xylose concentrations. It is plausible to assume that the co-utilisation of the sugars will be improved in such a system, because the cells that experience low glucose levels will take up more xylose.

It has been shown that the most efficient transport of xylose is achieved by strains overexpressing single hexose transporter genes in the order $H X T 7>H X T 5>$ GAL2 > HXT1 > HXT4 [9]. HXT7 was also reported to be the best xylose transporter in another study [8]. Encapsulation of yeast has been shown to lead to higher expression of Hxt6/7p, at glucose levels outside the capsules of more than $10 \mathrm{~g} / \mathrm{l}$ [15]. This is a strong indication that cells in different parts of the capsule have differences in physiology, in that some cells can sense low while others sense high concentrations of glucose. It also indicates that xylose uptake may be stimulated by encapsulation.

Based on this hypothesis, we simulated the sugar consumption of cells in a capsule half-filled with yeast, using finite element modelling, and a kinetic model for glucose and xylose uptake and conversion of furfural and 5hydroxymethylfurfural (HMF). The simulations showed that the simultaneous utilisation of glucose and xylose would indeed benefit from encapsulation, especially in an inhibitory medium. To validate these results, a xyloseutilising strain of yeast was constructed and encapsulated. The fermentation performance was compared with that of the same yeast in suspended culture in defined inhibitory media and dilute acid spruce hydrolysate.

\section{Results and discussion}

\section{Finite element modelling shows increased} co-consumption due to encapsulation

Mathematical modelling was implemented to visualise the effect of mass transport resistances on the concentration profiles of glucose, xylose, HMF and furfural in a capsule, and to analyse the sensitivity of the sugar consumption rates to different characteristics of the system.

The base case model of the diffusion and reaction rates resulted in very low concentrations of glucose and furfural in large parts of the cell pellet (Figure 1). In the centre of the pellet, the steady state glucose and furfural concentrations were $0 \mathrm{mM}$ because of rapid conversion of these compounds by the cells closer to the surface of the cell pellet. By contrast, the minimum concentrations of xylose and $\mathrm{HMF}$ were $0.1 \mathrm{mM}$ and $1.1 \mathrm{mM}$, respectively, because of the lower conversion rates. These results indicate that the overall conversion rates of glucose and furfural are diffusion-limited, whereas the conversion rates of xylose and HMF may be limited by the intrinsic reaction rate. 


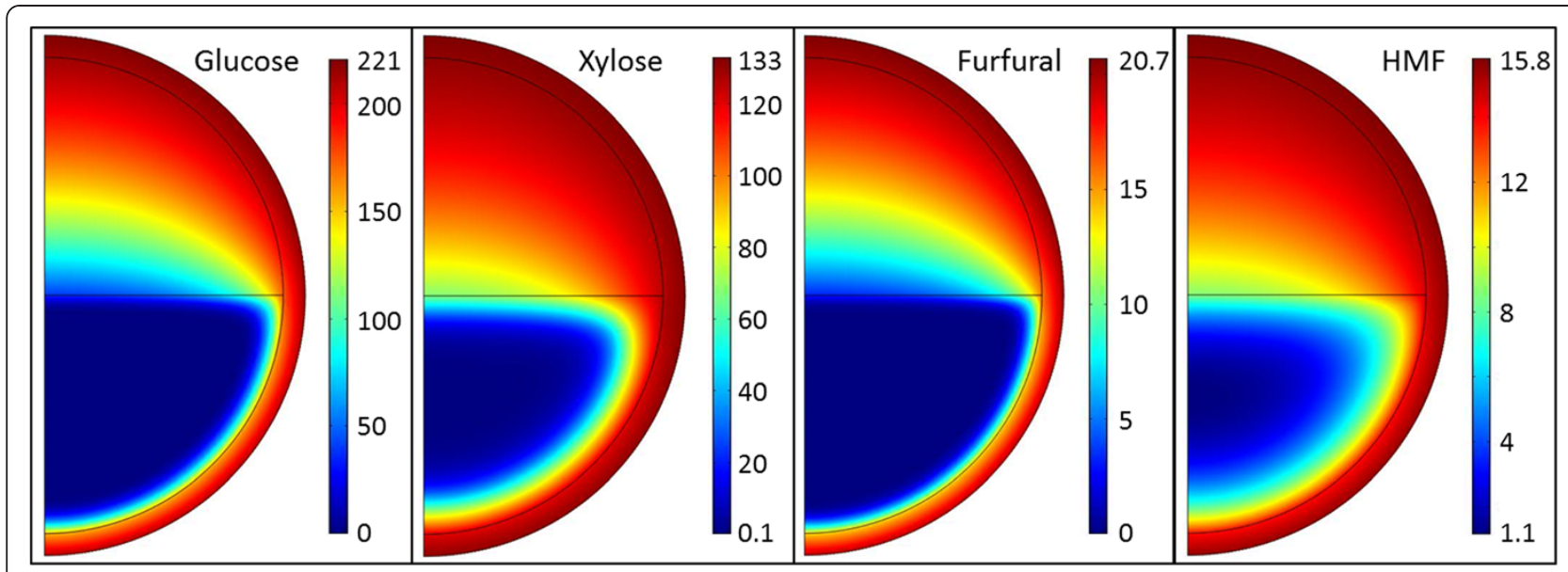

Figure 1 Simulated concentration gradients in capsules. Simulated concurrent local concentrations of glucose, xylose, furfural and 2-hydroxymethylfurfural (HMF) at steady state in liquid core capsules half-filled with cells, calculated using finite element modelling in 2D axisymmetrical geometry and base case parameter values. Reactions occurred only in the cell pellet in the lower half of the capsule. Numbers are in $\mathrm{mmol} / \mathrm{l}$. The maximum values were equal to the concentrations in the surrounding medium. For details, see Materials and Methods.

They also indicate that there are zones in the cell pellet where the inhibition of xylose consumption by glucose, furfural and HMF should be low.

Efficiency factors were calculated to compare the simulated results for encapsulated cells with well-mixed conditions and suspended cells. The efficiency factors were obtained by dividing the overall conversion rates with the conversion rates obtained using $10^{5}$ times higher effective diffusivities and otherwise identical parameter values. We verified that the higher diffusivities abolished all concentration gradients in the capsule and cell pellet and, therefore, these correspond to well-mixed conditions, with all concentrations being constant and equal to the external bulk concentrations. The calculated efficiency factors showed that the encapsulation increased the xylose consumption by a factor of 39.8 , and reduced the glucose consumption by a factor of 0.33 , compared with wellmixed conditions under the base case conditions (Table 1). The efficiency factor for xylose was much larger than 1 in all the tested cases, indicating that xylose consumption always benefits from encapsulation. The straightforward explanation for this is that encapsulation or more precisely, the tight agglomeration of cells, reduces local glucose concentration, which leads to lower inhibition of the xylose uptake.

By contrast, the efficiency factors for glucose uptake were generally less than 1 , indicating that mass transport becomes limiting for the glucose consumption (Table 1). However, when we increased the inhibition of glucose metabolism by furfural and HMF by decreasing the inhibition constants, glucose consumption also benefitted from the encapsulation. When the inhibition constants were set to $K_{i f}=5 \mathrm{mM}$ and $K_{i h}=10 \mathrm{mM}$, encapsulation increased the glucose and xylose consumption rates by 1.69 and 222 times, respectively, compared with wellmixed conditions.

Many of the parameter values used were rather uncertain. For the effective diffusivities, conservative estimates of the mass transfer resistances were used. For the cell pellet, the effective diffusivities were assumed to be $25 \%$ of the diffusivities in the surrounding liquid. In comparison, the effective diffusivity of glucose in flocs (that is, unencapsulated cell pellets) of S. cerevisiae NRRL Y265 has been shown to be 7 to $17 \%$ of that in the surrounding water [16]. Furthermore, the external mass transfer resistance was ignored, and the diffusivities in the gel membrane and liquid core were assumed to be close to or equal to the diffusivity in water [17-20]. All these assumptions should lead to underestimated concentration gradients (that is, overestimated concentrations), inside the capsules, and therefore, the predicted effects of encapsulation should be conservative estimates. Furthermore, it would be very difficult to identify and validate, for example, $K_{M}$ values and maximum glucose uptake rates, as these inevitably vary along the radius of the cell pellet, owing to the varying glucose concentration and the consequential differential expression of the hexose transporters.

Rate response coefficients and efficiency response coefficients were calculated in order to investigate the sensitivity of the simulation results to changes in different parameters (Table 1). The glucose consumption rate was clearly increased at higher diffusivities, with rate response coefficient $C_{D_{c}}^{R_{\text {Glucose }}}=0.34$. It was also clearly increased by higher biomass concentration in the pellet and by 
Table 1 Efficiency factors $\left(\beta_{j}\right)$, rate response coefficients $\left(C_{p}^{R_{j}}\right)$ and efficiency response coefficients $\left(C_{p}^{\beta_{j}}\right)$ for glucose and xylose for the base case and various simulated system changes

\begin{tabular}{|c|c|c|c|c|c|c|c|}
\hline Condition & Modified parameters $(P)$ & $\beta_{\text {glucose }}$ & $\beta_{\text {xylose }}$ & $C_{P}^{R_{\text {glucose }}}$ & $C_{P}^{R_{\text {xylose }}}$ & $C_{P}^{\beta_{\text {glucose }}}$ & $C_{P}^{\beta_{\text {xylose }}}$ \\
\hline Base case & See Table 3 and Figure 1 & 0.33 & 39.8 & - & - & - & - \\
\hline High xylose & $c_{x}=40 \mathrm{~g} / \mathrm{l}$ & 0.35 & 36.6 & - & - & - & - \\
\hline High furfural and HMF & $c_{f}=4 \mathrm{~g} / \mathrm{l} ; c_{h}=4 \mathrm{~g} / \mathrm{l}$ & 0.46 & 56.8 & - & - & - & - \\
\hline No furfural and HMF & $c_{f}=0 \mathrm{~g} / \mathrm{l} ; c_{h}=0 \mathrm{~g} / \mathrm{l}$ & 0.20 & 23.5 & - & - & - & - \\
\hline Strong inhibition by furfural and HMF & $K_{i f}=5 \mathrm{mM} ; K_{i h}=10 \mathrm{mM}$ & 1.69 & 222 & - & - & - & - \\
\hline \multirow[t]{2}{*}{ Biomass concentration } & $C_{\text {cells }}=270 \mathrm{~g} / \mathrm{l}$ & 0.35 & 41.7 & \multirow{2}{*}{-0.38} & \multirow{2}{*}{0.55} & \multirow{2}{*}{-0.62} & \multirow{2}{*}{-0.45} \\
\hline & $C_{c e l / s}=330 \mathrm{~g} / \mathrm{l}$ & 0.31 & 38.1 & & & & \\
\hline \multirow[t]{2}{*}{ Maximum glucose uptake rates } & $v_{\text {gmax }, L}=5.4 \mathrm{mmol} / \mathrm{g} / \mathrm{h} ; v_{\text {gmax }, H}=1.8 \mathrm{mmol} / \mathrm{g} / \mathrm{h}$ & 0.35 & 38.5 & \multirow{2}{*}{-0.33} & \multirow{2}{*}{0.31} & \multirow{2}{*}{-0.67} & \multirow{2}{*}{0.31} \\
\hline & $v_{\text {gmax }, L}=6.6 \mathrm{mmol} / \mathrm{g} / \mathrm{h} ; v_{\text {gmax }, H}=2.2 \mathrm{mmol} / \mathrm{g} / \mathrm{h}$ & 0.31 & 41.0 & & & & \\
\hline \multirow[t]{2}{*}{ Maximum xylose uptake rate } & $v_{x \max }=5.4 \mathrm{mmol} / \mathrm{g} / \mathrm{h}$ & 0.33 & 43.3 & \multirow{2}{*}{-0.01} & \multirow{2}{*}{0.20} & \multirow{2}{*}{0.01} & \multirow{2}{*}{-0.80} \\
\hline & $v_{x \max }=6.6 \mathrm{mmol} / \mathrm{g} / \mathrm{h}$ & 0.33 & 36.9 & & & & \\
\hline \multirow[t]{2}{*}{ Inhibition of glucose uptake by xylose } & $K_{i x}=32.4 \mathrm{mM}$ & 0.33 & 39.5 & \multirow{2}{*}{-0.07} & \multirow{2}{*}{0.08} & \multirow{2}{*}{-0.09} & \multirow{2}{*}{0.08} \\
\hline & $K_{i x}=39.6 \mathrm{mM}$ & 0.32 & 40.1 & & & & \\
\hline \multirow{2}{*}{$\begin{array}{l}\text { Inhibition of glucose and xylose uptake } \\
\text { by furfural and HMF }\end{array}$} & $K_{i f}=36 \mathrm{mM} ; K_{i h}=72 \mathrm{mM}$ & 0.34 & 41.8 & \multirow{2}{*}{-0.09} & \multirow{2}{*}{0.06} & \multirow{2}{*}{-0.42} & \multirow{2}{*}{-0.45} \\
\hline & $K_{i f}=44 \mathrm{mM} ; K_{i h}=88 \mathrm{mM}$ & 0.32 & 38.2 & & & & \\
\hline \multirow[t]{2}{*}{ Inhibition of xylose uptake by glucose } & $K_{i g}=0.36 \mathrm{mM}$ & 0.33 & 43.9 & \multirow{2}{*}{-0.00} & \multirow{2}{*}{0.07} & \multirow{2}{*}{0.00} & \multirow{2}{*}{-0.93} \\
\hline & $K_{i g}=0.44 \mathrm{mM}$ & 0.33 & 36.5 & & & & \\
\hline \multirow[t]{2}{*}{ Effective diffusivity in the cell pellet } & $\begin{array}{l}D_{c, \text { glucose }}=1.52 \times 10^{-10} \mathrm{~m}^{2} / \mathrm{s} ; D_{c, x y l o s e}=1.73 \times 10^{-10} \mathrm{~m}^{2} / \mathrm{s} ; \\
D_{c, \text { furfural }}=2.52 \times 10^{-10} \mathrm{~m}^{2} / \mathrm{s} ; D_{c, \text { HMF }}=2.39 \times 10^{-10} \mathrm{~m}^{2} / \mathrm{s}\end{array}$ & 0.32 & 38.2 & \multirow{2}{*}{0.34} & \multirow{2}{*}{0.39} & \multirow{2}{*}{0.34} & \multirow{2}{*}{0.39} \\
\hline & $\begin{array}{l}D_{c, \text { glucose }}=1.86 \times 10^{-10} \mathrm{~m}^{2} / \mathrm{s} ; D_{c, \text { xylose }}=2.11 \times 10^{-10} \mathrm{~m}^{2} / \mathrm{s} ; \\
D_{c, \text { furfural }}=3.08 \times 10^{-10} \mathrm{~m}^{2} / \mathrm{s} ; D_{c, \text { HMF }}=2.92 \times 10^{-10} \mathrm{~m}^{2} / \mathrm{s}\end{array}$ & 0.34 & 41.3 & & & & \\
\hline
\end{tabular}

HMF, 5-hydroxymethylfurfural.

higher maximum glucose uptake rates $\left(C_{C_{\text {cells }}}^{R_{\text {Glucose }}}=0.38\right.$, $\left.C_{v_{g m a x}}^{R_{\text {clucose }}}=0.33\right)$. However, although increased diffusivity also led to an increased efficiency factor for glucose $\left(C_{D_{c}}^{\beta_{\text {Glucose }}}=0.34\right)$, increased biomass concentration and maximum rates actually decreased the efficiency factor $\left(C_{C_{\text {cells }}}^{\beta_{\text {Glucose }}}=-0.62, C_{v_{\text {gmax }}}^{\beta_{\text {Glucose }}}=-0.67\right)$. This clearly shows that the glucose consumption rate is diffusionlimited. The glucose uptake efficiency factor increased in response to inhibition by furfural and HMF, and to a smaller extent in response to increased xylose inhibition. At sufficiently strong inhibition, even glucose uptake benefits from encapsulation, as already mentioned above.

The xylose consumption rate was even more sensitive to increased biomass concentration and equally sensitive to $v_{\text {gmax }}$, but for xylose the efficiency response coefficient increased in response to $v_{\text {gmax }}$. Moreover, the efficiency factor for the xylose consumption increased with stronger inhibition (that is, lower $K_{i}$ ) by glucose, furfural and HMF $\left(C_{K_{i g}}^{\beta_{\text {Xylose }}}=-0.93, C_{K_{i f}, K_{i h}}^{\beta_{\text {Xylose }}}=-0.45\right)$. In summary, encapsulation becomes very favourable for xylose consumption if the inhibition effects are strong and the glucose concentration in the capsule can be kept low.

\section{Construction of the xylose-fermenting S. cerevisiae CEN.PK XXX}

A xylose-fermenting strain, which we named CEN.PK $\mathrm{XXX}$, was constructed by overexpression of the native RPE1, TAL1, RKI1 and XKS1 genes, and insertion of codon-optimised XYL1 and XYL2 genes from Scheffersomyces stipitis (formerly Pichia stipitis) into the genome of $S$. cerevisiae CEN.PK 122 MDS. The cells were shown to assimilate xylose in repeated rounds of dilutions to $\mathrm{OD}_{600}=0.1$ and semi-aerobic growth up to $\mathrm{OD}_{600}=12$ to 13 in 3 days.

\section{Encapsulation of a xylose-fermenting S. cerevisiae to validate simulation results}

To test the hypothetical results of the simulations, $S$. cerevisiae CEN.PK XXX was encapsulated and utilised for anaerobic batch cultivations in various media. The fermentations were operated for 96 hours, except for those with suspended yeast in medium without xylose, which were stopped after 30 hours, because all the glucose was consumed by that time.

The encapsulated cells did not show a lag phase prior to glucose consumption, whereas a lag phase was observed for the freely suspended cells in all cases except when furfural was absent (Figure 2A,B). This is in 

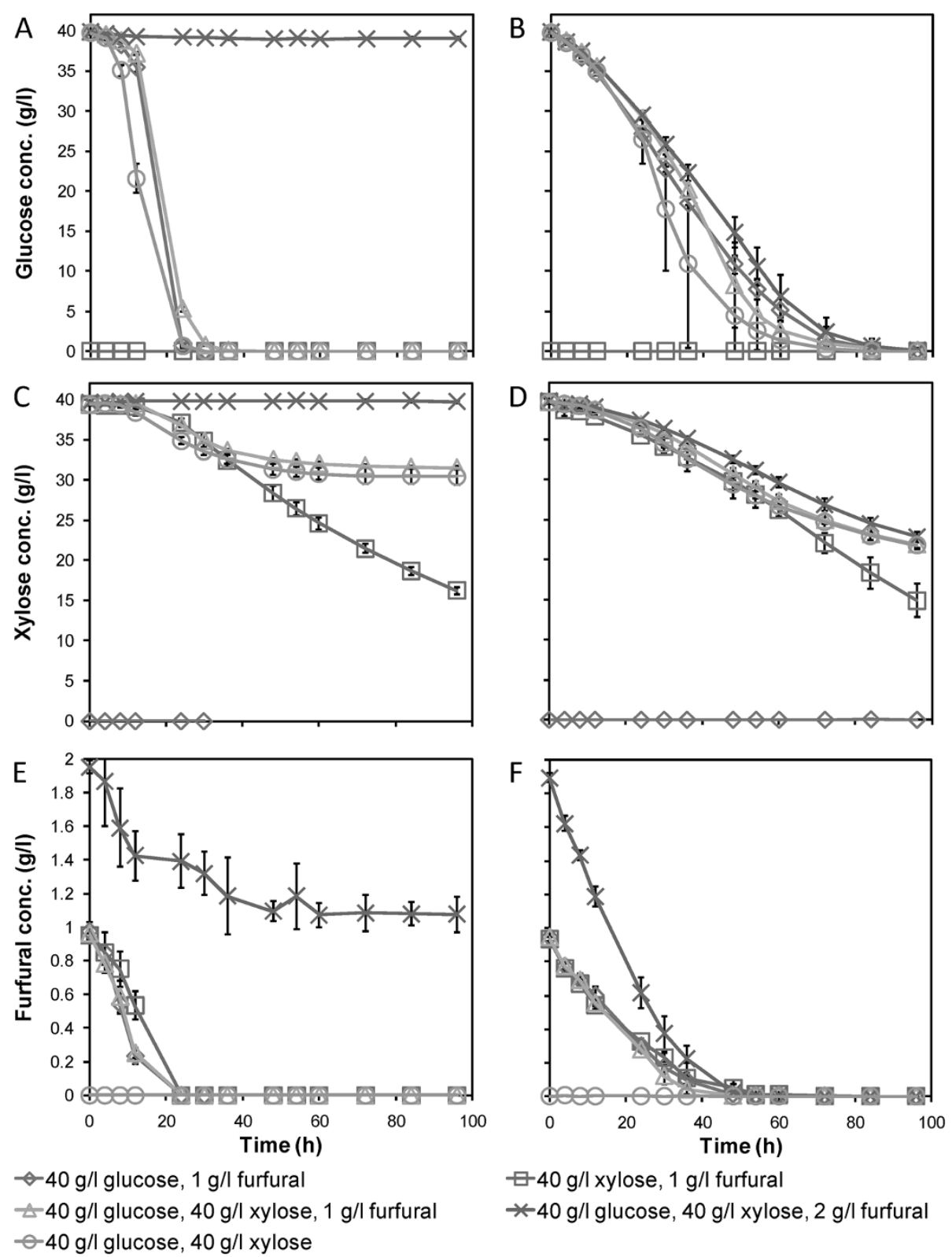

$\square 40 \mathrm{~g} / \mathrm{l} x y l o s e, 1 \mathrm{~g} / \mathrm{l}$ furfural

$* 40 \mathrm{~g} / \mathrm{l}$ glucose, $40 \mathrm{~g} / \mathrm{l}$ xylose, $2 \mathrm{~g} / \mathrm{l}$ furfural

Figure 2 Concentrations of glucose, xylose and furfural during fermentation of defined media by suspended and encapsulated xylosefermenting yeast. (A-F) Concentrations of glucose, xylose and furfural for (A, C, E) freely suspended and (B, D, F) encapsulated Saccharomyces cerevisiae CEN.PK XXX in anaerobic batch cultures on defined media containing different initial concentrations of glucose, xylose and furfural. Average values \pm 1 standard deviation, $n=3$.

agreement with previous observations [21]. The absence of a lag phase for encapsulated cells would be expected if there were concentration gradients of inhibitors inside the capsules [14]. The furfural would only inhibit the cells close to the membrane for encapsulated cells. Sugars that diffuse through the capsule membrane and the cell pellet would be fermented by cells further into the pellet already at the beginning of the cultivation.

For the suspended cells, rapid glucose consumption began only after the furfural was present at concentrations below 0.7 to $0.8 \mathrm{~g} / \mathrm{l}$, which occurred 8 to 24 hours into the cultivations (Figure 2A,C,E). Furthermore, suspended CEN.PK XXX at this cell concentration did not tolerate a furfural concentration of $2 \mathrm{~g} / \mathrm{l}$. The cells managed to convert less than half of the furfural present, without visible glucose or xylose consumption. However, when encapsulated, the cells in the medium with $2 \mathrm{~g} / \mathrm{l}$ furfural exhibited only a somewhat slower uptake of both glucose and xylose compared with cells in the other media (Figure 2B,D). 


\section{Improved simultaneous co-utilisation of glucose and xylose by encapsulation}

The xylose consumption was rather similar between the encapsulated and freely suspended yeast cells when xylose was the only carbon source (Figure 2C,D). Hence, the diffusion limitations observed for glucose, which led to slower utilisation, was not a limitation for xylose utilisation, confirming the results of the simulations.

In media with both xylose and glucose, there were significant differences between the free and encapsulated cells. The suspended cells displayed some co-consumption of the two sugars, with approximately $6.5 \mathrm{~g} / \mathrm{l}$ reduction in the xylose concentration concomitant with the consumption of all glucose. This consumption was accompanied by a high production of glycerol, but very low accumulation of xylitol (Figure 3). The glycerol production helped to reoxidise NADH, therefore, virtually all xylitol could be converted to xylulose. When the glucose was depleted, xylitol started to accumulate, most likely due to a lack of $\mathrm{NAD}^{+}$, as the high glycerol production could not be
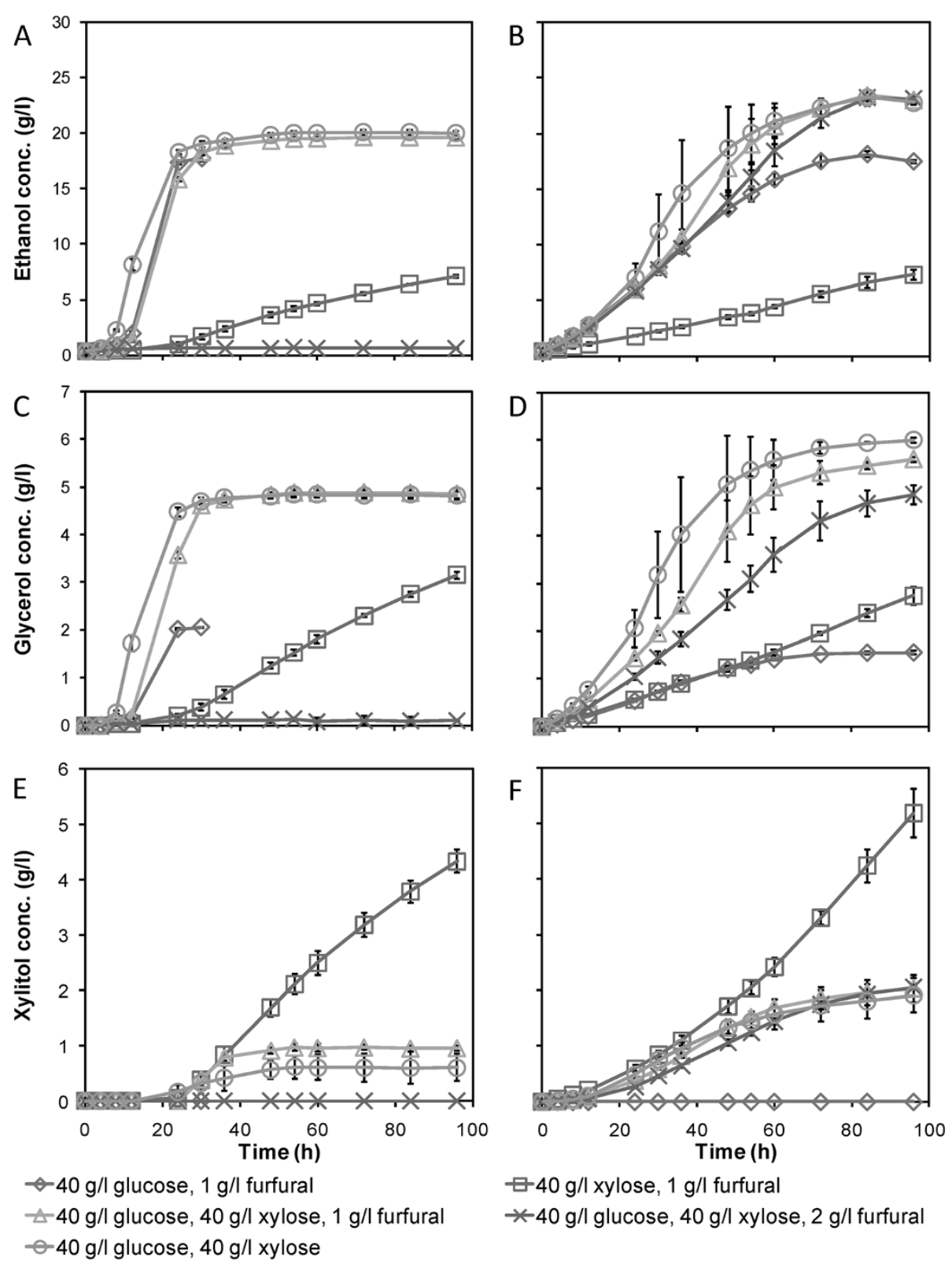

Figure 3 Concentrations of ethanol, glycerol and xylitol during fermentation of defined media by suspended and encapsulated xylosefermenting yeast. (A-F) Concentrations of ethanol, glycerol and xylitol for (A, C, E) freely suspended and (B, D, F) encapsulated Saccharomyces cerevisiae CEN.PK XXX in anaerobic batch cultures on defined media containing different initial concentrations of glucose, xylose and furfural. Average values \pm 1 standard deviation, $n=3$. 
maintained. Xylose consumption almost ceased at a residual xylose concentration of about $30 \mathrm{~g} / \mathrm{l}$, approximately 24 hours after glucose depletion. This slow xylose utilisation after glucose depletion has been observed previously [7]. The exact reason is not known, but tentatively, ceased glucose metabolism may lead to a lack of intermediary metabolites for the initial steps of xylose metabolism and the pentose phosphate pathway, leading to reduced rates [7]. When no more glucose is consumed, there might be a shortage of both NADPH and $\mathrm{NAD}^{+}$, generated through the oxidative pentose phosphate pathway and from glycerol production, respectively. Severe redox imbalance problems could then be the reason for the extremely slow xylose consumption after glucose exhaustion, as suggested by Kim et al. [22]. Alternatively, simultaneous consumption of glucose and xylose can facilitate more efficient conversion of xylose, xylitol and xylulose into glycolytic intermediates and subsequently into ethanol. Tentatively, the cells are in a highly metabolically active state at the point of glucose depletion, and they might not be able to adapt quickly enough to the rapid drop in NADPH and $\mathrm{NAD}^{+}$expected during pure anaerobic xylose utilisation. Moreover, ATP depletion can occur, if xylose, which at that time was the only carbon source, is used for glycerol production to reoxidise NADH rather than for substrate level phosphorylation in glycolysis. If xylulokinase activity is too high, this can also lead to depletion of ATP [23]. With xylose present as the only carbon and energy source already from the start of the fermentation, the cells probably adapted their metabolism and maintained the redox balance. Therefore, a decrease in xylose consumption rate was not observed in this case (Figure 2C).

The encapsulated CEN.PK XXX fermented xylose from the beginning of the batches, regardless of the initial furfural concentration. A slight reduction in the uptake rate of xylose was observed as the glucose was depleted in the media with mixed carbohydrates (Figure 2D). However, the final uptake of xylose after 96 hours was significantly better for the encapsulated cells than for the freely suspended cells in media containing glucose. The final residual xylose concentrations were 21.4 to $23.4 \mathrm{~g} / \mathrm{l}$. Hence, encapsulated $S$. cerevisiae CEN.PK XXX consumed at least $50 \%$ more xylose than the freely suspended cells, under the same conditions. This significant difference was also clearly visible in the ethanol production, and resulted in approximately 15\% higher final concentrations (Figure 3).

Tentatively, a large portion of the encapsulated cells will have experienced glucose concentrations of zero or close to zero throughout the batches containing glucose and xylose, as observed in the simulations. In this sense, these cells resembled cells in medium with only xylose present, with a balanced metabolism occurring throughout the batch. In contrast to suspended cells, these cells will thus not experience a huge difference upon glucose depletion. Hence, sudden large redox imbalances, or ATP depletion, at the end of the glucose consumption phase are probably not present for most of the encapsulated cells. However, the cells close to the membrane might have been disturbed by the change in metabolism, and this may have caused the small decrease in xylose consumption observed after glucose depletion.

The total ethanol yields on consumed glucose during the course of the fermentation show that the encapsulated cells utilised glucose and xylose more simultaneously and more efficiently than the freely suspended yeast, corroborating the results from the simulations (Figure 4). For the suspended yeast, the total ethanol yield on glucose at 24 hours was slightly higher in the mixed carbohydrate
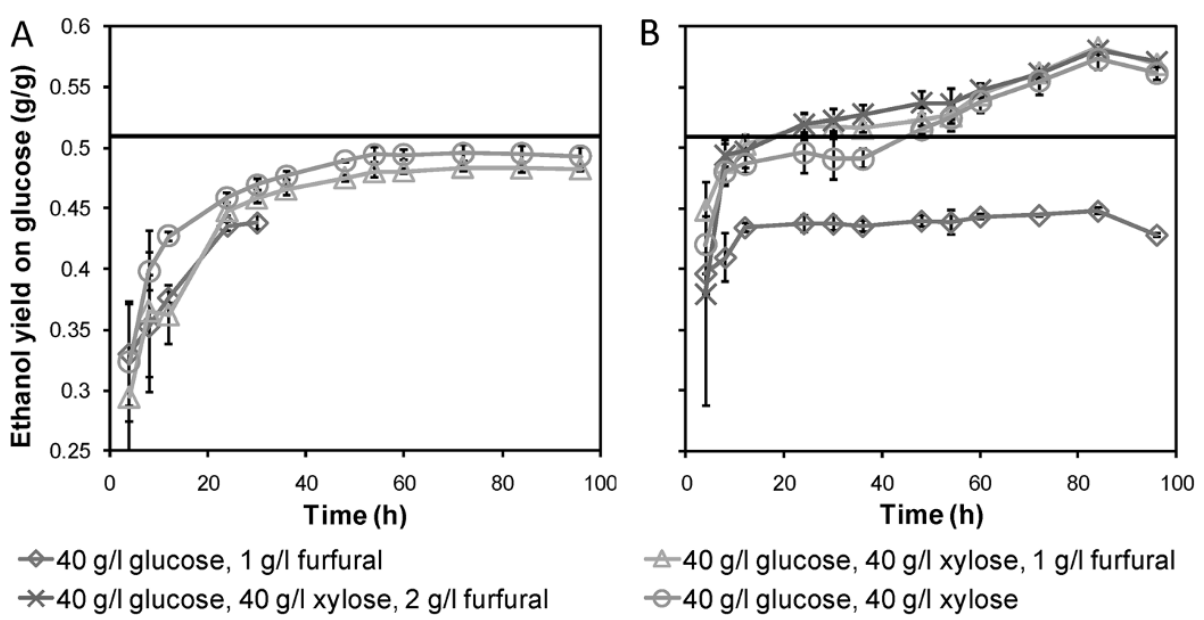

Figure 4 Cumulative total yield of ethanol on glucose during fermentation of defined media. (A) Suspended and (B) encapsulated xylosefermenting yeast. The total ethanol yield was calculated from the glucose consumption and total ethanol production from both xylose and glucose from the beginning of the batch to each sample point. The theoretically highest possible ethanol yield on glucose only (0.51 g/g) is indicated by the black line. Yields higher than this level indicate ethanol production from $x y l o s e$. Average values \pm 1 standard deviation, $\mathrm{n}=3$. 
cultures than in those with glucose as the sole carbon source. This indicates that co-utilisation had taken place. However, for the encapsulated yeast, the cultures with mixed carbohydrates exhibited a higher ethanol yield throughout the course of the fermentation. Early in the batches, this yield exceeded the theoretical maximum for ethanol production from glucose only $(0.51 \mathrm{~g} / \mathrm{g})$, as indicated by the black horizontal line in Figure 4. The final ethanol yield on glucose was up to $33 \%$ higher with the mixed sugars than with glucose only, clearly showing that the encapsulated yeast produced ethanol from xylose throughout the batches.

For the suspended cells, most of the xylose consumption took place at low glucose levels. This was especially the case in the medium without furfural. After 12 hours, almost half of the glucose had been consumed, with only about $1 \mathrm{~g} / \mathrm{l}$ of xylose consumed simultaneously (Figure 2A,C). By contrast, the encapsulated yeast already showed co-consumption of the two sugars at the high glucose concentrations at the beginning of the cultivations. Furthermore, we observed that the co-utilisation of xylose by the encapsulated cells increased during the course of the fermentations. We suggest this occurs because the capsules fill up with cells, increasing the effect of concentration gradients in the cell pellets.

The cells in the cultivation without furfural displayed less co-consumption of the glucose and xylose (Figure 4). Owing to occasional breakage of capsules during the precultivations, yeast cells clinging to the outside of the capsules were sometimes transferred with the capsules into the anaerobic batch cultivations. In some cases, cells grew outside the capsules, especially when no furfural remained in the medium. This led to faster glucose consumption and hence less co-utilisation of xylose. Therefore, the error bars are disproportionately high for zero and low initial concentrations of furfural for the encapsulated yeast. However, this does not compromise the conclusions drawn from this study.

\section{Product yields}

The encapsulated yeast utilised the sugars in a rather similar fashion to the freely suspended yeast (Table 2). However, with only xylose present, the glycerol yield was higher for the encapsulated than the suspended yeast, opposite to the results observed for glucose only both in this study (Table 2) and a previous study [15]. Furthermore, the glycerol yields decreased with increasing furfural concentration for the encapsulated cells. This happens because the furfural acts as a redox sink, reoxidising NADH during its conversion into furfuryl alcohol [24]. This effect was not observed for the suspended cells, because the conversion of furfural occurred before consumption of sugars in those cultivations. The xylitol yields were generally higher for the encapsulated than for the suspended cells (Table 2). This could be an effect of stricter anaerobic conditions for the encapsulated cells, leading to accumulation of more xylitol [5]. Oxygen was not actively stripped from the shake flasks at the start of the batch fermentations, and oxygen would not reach the encapsulated cells as readily as it would reach the freely suspended cells. The higher glycerol yield on xylose, which led to reoxidation of NADH to $\mathrm{NAD}^{+}$, which is needed for xylitol oxidation, can be explained in the same way. The ethanol yields on the two sugars were rather similar overall between the two modes of cultivation, with a slightly lower yield for the encapsulated cells as they consumed more xylose. We observed from the results that CEN.PK XXX was able to grow anaerobically on xylose as the sole carbon source at relatively high biomass yields (Table 2). However, it should again be stressed that there was some oxygen present in the flasks at the start of the anaerobic fermentations and the biomass was measured only at the end.

Table 2 Final yields and carbon recoveries in anaerobic batch fermentations of defined media ${ }^{a}$

\begin{tabular}{|c|c|c|c|c|c|c|c|}
\hline & Medium $^{\mathbf{b}}$ & $Y_{\text {SGly }}$ & $\mathrm{Y}_{\text {SAce }}$ & $Y_{\text {SXylitol }}$ & $Y_{\text {SBiomass }}$ & $\mathrm{Y}_{\text {SEtOH }}$ & Carbon balance (\%) \\
\hline \multirow[t]{5}{*}{ Freely suspended CEN.PK XXX } & G40 F1 & $52 \pm 1$ & $3 \pm 0$ & NA & $48 \pm 0$ & $438 \pm 6$ & $97 \pm 1$ \\
\hline & X40 F1 & $83 \pm 6$ & $8 \pm 3$ & $187 \pm 6$ & $41 \pm 1$ & $290 \pm 0$ & $94 \pm 1$ \\
\hline & $\mathrm{G} 40 \times 40$ & $99 \pm 1$ & $5 \pm 1$ & $67 \pm 21$ & $38 \pm 0$ & $402 \pm 1$ & $94 \pm 1$ \\
\hline & $\mathrm{G} 40 \times 40 \mathrm{~F} 1$ & $102 \pm 2$ & $3 \pm 0$ & $121 \pm 9$ & $37 \pm 1$ & $402 \pm 1$ & $95 \pm 1$ \\
\hline & G40 X40 F2 & $\mathrm{NA}$ & $\mathrm{NA}$ & $\mathrm{NA}$ & NA & $\mathrm{NA}$ & $\mathrm{NA}$ \\
\hline \multirow[t]{5}{*}{ Encapsulated CEN.PK XXX } & G40 F1 & $39 \pm 1$ & $2 \pm 1$ & $\mathrm{NA}$ & $47 \pm 3$ & $428 \pm 2$ & $93 \pm 1$ \\
\hline & X40 F1 & $111 \pm 0$ & $3 \pm 1$ & $209 \pm 4$ & $55 \pm 2$ & $277 \pm 3$ & $92 \pm 1$ \\
\hline & $\mathrm{G} 40 \times 40$ & $104 \pm 1$ & $3 \pm 0$ & $106 \pm 15$ & $32 \pm 3$ & $387 \pm 1$ & $93 \pm 2$ \\
\hline & G40 X40 F1 & $97 \pm 2$ & $2 \pm 0$ & $114 \pm 9$ & $30 \pm 1$ & $393 \pm 1$ & $94 \pm 1$ \\
\hline & $\mathrm{G} 40 \times 40 \mathrm{~F} 2$ & $86 \pm 2$ & $1 \pm 0$ & $122 \pm 5$ & $29 \pm 2$ & $401 \pm 2$ & $94 \pm 1$ \\
\hline
\end{tabular}

Abbreviations: NA not applicable.

${ }^{a}$ Yields are shown as mg product per g consumed sugar (average values \pm 1 standard deviation, $\left.n=3\right)$. Acetate $\left(Y_{S A c e}\right)$, ethanol $\left(Y_{S E t O H}\right)$, glycerol $\left(Y_{S G l y}\right)$ and biomass $\left(\mathrm{Y}_{\mathrm{SBiomass}}\right)$ yields were calculated on total consumed sugars, whereas the xylitol $\left(\mathrm{Y}_{\mathrm{Sxy} \text { litol }}\right)$ yield was calculated on consumed $\mathrm{xylose}$ only.

${ }^{\mathrm{b}} \mathrm{G} 40$ : glucose $40 \mathrm{~g} / \mathrm{l} ; \mathrm{X} 40$ : xylose $40 \mathrm{~g} / \mathrm{l} ; \mathrm{F} 1$ : furfural $1 \mathrm{~g} / \mathrm{l} ; \mathrm{F} 2$ : furfural 2 g/l. 
The biomass yields were generally lower for the encapsulated cells.

\section{Encapsulation solves two issues of lignocellulosic hydrolysate fermentation}

To investigate the overall performance of encapsulated cells, and as a proof of concept, fermentation of a spruce hydrolysate was investigated with encapsulated and freely suspended S. cerevisiae CEN.PK XXX. We observed that the encapsulated cells were able to consume all sugars, except arabinose, starting from the beginning of the fermentation (Figure 5C). This occurred concurrently with in situ detoxification by conversion of furfural, and resulted in approximately $7 \%$ higher final ethanol concentration for the encapsulated than for the suspended yeast, $16.4 \pm 0.6$ $(\mathrm{n}=3)$ and $15.4 \pm 0.0(\mathrm{n}=2)$, respectively $(P<0.05$, onetailed $t$-test) (Figure 5).

Co-consumption of glucose, mannose, xylose and galactose was not observed for suspended yeast at glucose concentrations above $10 \mathrm{~g} / \mathrm{l}$ (Figure 5A,B). The suspended yeast did not start to consume notable amounts of any sugar until the hydrolysate was detoxified by conversion of the present furfural and HMF. After full conversion of the furfural, consumption of glucose and mannose occurred rapidly. Consumption of xylose and galactose by the suspended yeast was only observed once the concentration of glucose was low enough. The total amount of xylose consumed was also slightly lower for the freely suspended cells. Xylose consumption stopped shortly after glucose depletion, similar to the observations for the fermentations of defined media.

As a result of encapsulating the relatively sensitive laboratory strain $S$. cerevisiae CEN.PK XXX, the inhibitor tolerance of the system as a whole and its ability to simultaneously co-utilise glucose and xylose were improved. Another benefit of cell encapsulation, which has not been stressed in this work, is that the cells are easily retained in the reactor. Thus, the volumetric productivity can be easily improved by increasing the amount of capsules in the reactor.

\section{Conclusions}

Results from in silico simulations and in vivo experiments showed that encapsulation of a xylose-fermenting yeast strain increased the simultaneous utilisation of glucose and xylose and improved the tolerance to furfural. All the data indicate that the reason behind these results is that diffusion limitations cause concentration gradients of convertible inhibitors and glucose within the cell pellet. High local cell density, here in the form of encapsulated yeast, can thus help in overcoming two of the remaining obstacles for successful commercialisation of second-generation bioethanol production, namely,

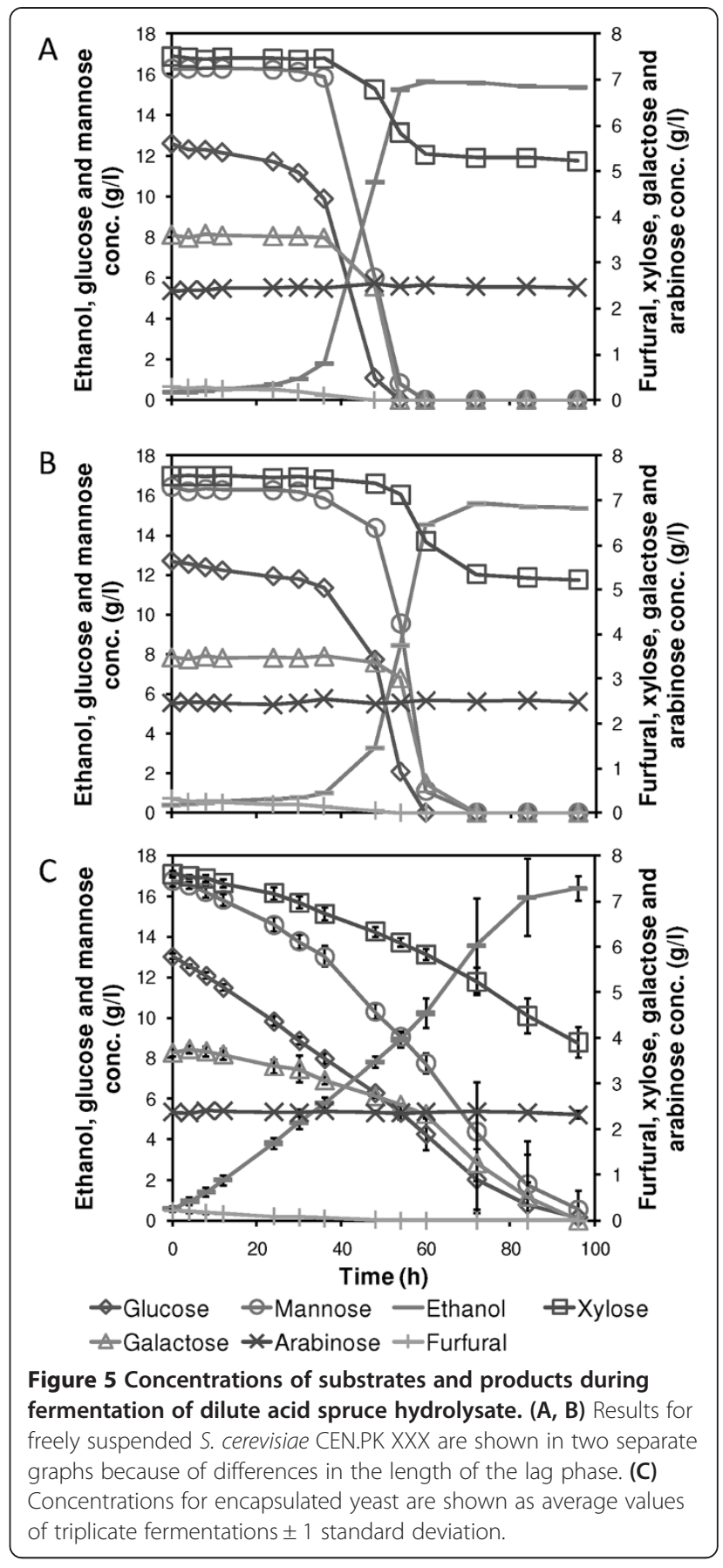

fermentation inhibitors and sequential hexose and pentose fermentation.

\section{Materials and methods}

\section{Mathematical modelling}

Diffusion and consumption of glucose, xylose, furfural and HMF by encapsulated cells was simulated using finite element modelling (FEM) and simplified kinetics. The Chemical Reaction Engineering Module in Comsol 
Multiphysics 4.3 (Comsol AB, Stockholm, Sweden) was used for all simulations.

\section{Physical description of capsules and meshing for FEM}

Capsules were assumed to be spherical with an outer radius of $2 \mathrm{~mm}$ (Figure 6). The spheres were divided into three compartments: a $0.17 \mathrm{~mm}$ thick membrane along the surface of the sphere, a liquid core and a cell pellet, each of the latter two occupying half of the core volume. To improve computational efficiency, the threedimensional capsule was modelled in two dimensions by assuming rotational symmetry.

The capsule was meshed in Comsol Multiphysics 4.3 (Comsol AB, Stockholm, Sweden) using the built-in free triangular mesh algorithm, with extra fine element size in the membrane and the liquid core, and extremely fine element size in the cell pellet.

\section{Kinetic description of cell metabolism}

Because the purpose of the mathematical modelling was only to visualise potential concentration gradients inside the capsules, yeast metabolism was modelled only with reactions consuming sugars and the inhibitors furfural and HMF. Thus, in the investigated time frames, growth and product formation were assumed to have negligible effects on the diffusion of sugars and inhibitors, and on the rates of consumption.

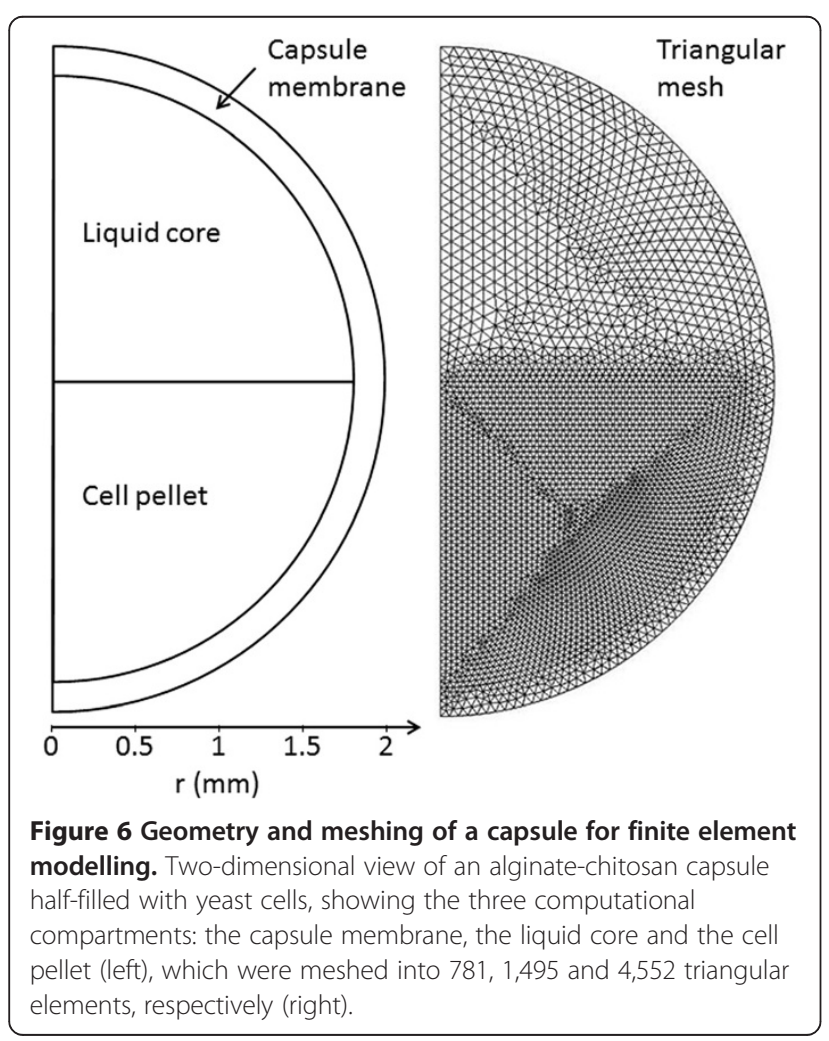

For the purpose of the model in this work, glucose uptake was modelled as a two-component system, consisting of a low and a high affinity transporter [25]. Xylose uptake was assumed to be facilitated by a single, lowaffinity system [25]. Because they are transported by the same hexose transporter system, each sugar was assumed to competitively inhibit the uptake of the other sugar [26]. Xylose was assumed to inhibit both glucose uptake systems with the same inhibition constant [25]. Moreover, both uptake rates were assumed to be non-competitively inhibited by furfural, and to a lesser extent by HMF.

Consequently, glucose and xylose consumption rates ( $v_{g}$ and $v_{x}$, respectively) were described by the rate equations

$$
\begin{aligned}
v_{g}= & \left(\frac{v_{g \max , L} C_{g}}{K_{M g, L}\left(1+\frac{C_{x}}{K_{i x}}\right)+C_{g}}+\frac{v_{g \max , H} C_{g}}{K_{M g, H}\left(1+\frac{C_{x}}{K_{i x}}\right)+C_{g}}\right) \\
& \left(\frac{1}{1+\frac{C_{f}}{K_{i f}}}\right)\left(\frac{1}{1+\frac{C_{h}}{K_{i h}}}\right)
\end{aligned}
$$

and

$$
v_{x}=\left(\frac{v_{x \max } C_{x}}{K_{M x}\left(1+\frac{C_{g}}{K_{i g}}\right)+C_{x}}\right)\left(\frac{1}{1+\frac{C_{f}}{K_{i f}}}\right)\left(\frac{1}{1+\frac{C_{h}}{K_{i h}}}\right)
$$

where $v_{\text {gmax }}$ and $v_{x \max }$ are the maximum specific rates of consumption (mmol/g dry cells/h); $C_{g}, C_{x}, C_{f}$ and $C_{h}$ are concentrations; $K_{M g}$ and $K_{M x}$ are half saturation constants; and $K_{i f}$ and $K_{i h}$ are inhibition constants. Indexes $g, x, f$ and $h$ refer to glucose, xylose, furfural and HMF, respectively, while $L$ and $H$ refer to the low and high affinity glucose transport systems, respectively.

The specific rates of conversion of the furan aldehydes $\left(v_{f}\right.$ and $\left.v_{h}\right)$ were described by Michaelis-Menten kinetics

$$
\begin{aligned}
& v_{f}=\frac{v_{\text {fmax }} C_{f}}{K_{M f}+C_{f}} \\
& v_{h}=\frac{v_{\text {hax }} C_{h}}{K_{M h}+C_{h}}
\end{aligned}
$$

\section{Boundary conditions and parameters}

All bulk concentrations, as well as kinetic parameters and diffusivities used in the modelling, are summarised in Table 3.

The biomass concentration inside the cell pellet compartment in the capsule was assumed to be constant at $300 \mathrm{~g} / \mathrm{l}$, as reported previously [15,30]. The concentrations of solutes in the bulk liquid outside the capsule 
Table 3 Bulk concentrations, kinetic parameters and diffusivities of glucose, xylose, furfural and HMF used as base case for mathematical modelling

\begin{tabular}{|c|c|c|c|c|c|c|c|}
\hline & $C_{\text {bulk }}, \mathrm{g} / \mathrm{l}$ & $v_{\text {max }}, \mathrm{mmol} / \mathrm{g} / \mathrm{h}$ & $K_{M}, \mathrm{mmol} / \mathrm{l}$ & $K_{i}, \mathrm{mmol} / \mathrm{l}$ & $D_{w}, \mathrm{~m}^{2} / \mathrm{s}$ & $D_{m}, \mathrm{~m}^{2} / \mathrm{s}$ & $D_{c}, \mathrm{~m}^{2} / \mathrm{s}$ \\
\hline Glucose & 40 & $6(\mathrm{~L}), 2(\mathrm{H})$ & $20(\mathrm{~L}), 0.4(\mathrm{H})$ & 36 (xylose), 40 (furfural), 80 (HMF) & $6.76 \times 10^{-10 a}$ & $6.08 \times 10^{-10}$ & $3.38 \times 10^{-10}$ \\
\hline Xylose & 20 & 6 & 100 & 0.4 (glucose), 40 (furfural), 80 (HMF) & $7.69 \times 10^{-10 a}$ & $6.92 \times 10^{-10}$ & $3.85 \times 10^{-10}$ \\
\hline Furfural & 2 & 3 & 0.7 & & $1.10 \times 10^{-9 b}$ & $9.90 \times 10^{-10}$ & $5.50 \times 10^{-10}$ \\
\hline HMF & 2 & 1 & 20 & & $1.06 \times 10^{-9 c}$ & $9.54 \times 10^{-10}$ & $5.30 \times 10^{-10}$ \\
\hline
\end{tabular}

Abbreviations: $C_{\text {bulk }}$ concentration in the bulk liquid; $D_{c}$ effective diffusivity in the cell pellet; $D_{m}$ effective diffusivity in the capsule membrane; $D_{w}$ diffusivity in the bulk and in the liquid core of the capsule; $H$ high affinity glucose transporter; HMF 5-hydroxymethylfurfural; $K$ half saturation constant (Michaelis-Menten constant); $K_{i}$ inhibition constant for each of the indicated compound; $L$ low-affinity glucose transporter; $v_{\text {max }}$ maximum specific consumption rate;

were set as constant boundary conditions. Parameters for glucose and xylose transport were adapted from Lee et al. [25]. The inhibition constant for competitive inhibition of xylose uptake by glucose was assumed to be equal to the high affinity $K_{M}$ value for glucose. For furfural consumption, the maximum rate and saturation constant identified during steady state conditions at high cell density in a membrane bioreactor were used [31]. HMF is generally consumed at a lower rate than furfural. It was assumed that the maximum rate of HMF conversion was one-third of the maximum furfural conversion rate, with a saturation constant of $20 \mathrm{mM}$ [32-34].

Inhibition by furfural and HMF can mostly be observed as an extended lag phase in batch cultures, during which primarily furfural is converted to furfuryl alcohol. This indicates very strong inhibition, but cannot be modelled in the relatively simple kinetic framework of the present study. Sárvári Horváth and co-workers estimated the specific growth rate during pulse additions of furfural to an anaerobic continuous culture of $S$. cerevisiae CBS8066 [24]. By fitting the model

$$
\hat{\mu}=D\left(\frac{1}{1+\frac{C_{f, p u l s e} / 2}{K_{i f}}}\right)
$$

to the measured specific growth rate using non-linear regression, we estimated the inhibition constant $K_{i f}$ is approximately $40 \mathrm{mM}$. In this equation, $\hat{\mu}$ is the estimated specific growth rate, $D$ is the dilution rate equalling the specific growth rate at steady state prior to each pulse addition, and $C_{f}$, pulse is the concentration of the furfural immediately after pulse addition. In the absence of reliable data, and as HMF is known to be less inhibitory than furfural, we set the inhibition constant $K_{i h}$ at $2 K_{i f}$.

Diffusivities in the liquid bulk were taken from literature data (Table 3). The effective diffusivities in the liquid core, gel membrane and cell pellet were assumed to be $100 \%, 90 \%$ and $25 \%$ of the diffusivity in the liquid bulk $\left(D_{w}\right)$, respectively. The Sherwood number was set to 100 to exclude external mass transfer resistance.

\section{Efficiency factors and sensitivity analysis}

To investigate the effect of encapsulation, the total rate of reaction in the two-dimensional cell pellet, $R(\mathrm{~mol} / \mathrm{m} / \mathrm{s})$, was calculated by surface integration for each of the four molecular species. An efficiency factor for each species $j, \beta_{j}$, was calculated by dividing the resulting overall reaction rate, $R_{j}\left(D_{w, i}\right)$, by the corresponding value obtained after increasing all diffusivities by a factor of $10^{5}, R_{j}\left(D_{w, i} \times 10^{5}\right)$, to emulate well-mixed conditions:

$$
\beta_{j}=\frac{R_{j}\left(D_{w, i}\right)}{R_{j}\left(D_{w, i} \cdot 10^{5}\right)}
$$

To assess the sensitivity of the system to one or a group of parameters, the total rates and efficiency factors were calculated at $10 \%$ lower and $10 \%$ higher values of the selected parameters. In analogy to metabolic response coefficients, the relative change in rates and efficiency due to the relative change in the parameter value, were calculated by

$$
\begin{aligned}
& C_{P}^{R_{j}}=\frac{d \ln R_{j}}{d \ln P} \approx \frac{\ln R_{j}(1.1 P)-\ln R_{j}(0.9 P)}{\ln 1.1 P-\ln 0.9 P} \\
& C_{P}^{\beta_{j}}=\frac{d \ln \beta_{j}}{d \ln P} \approx \frac{\ln \beta_{j}(1.1 P)-\ln \beta_{j}(0.9 P)}{\ln 1.1 P-\ln 0.9 P}
\end{aligned}
$$

where $C_{P}^{R_{j}}$ and $C_{P}^{\beta_{j}}$ are the rate and efficiency response coefficients to the parameter $P$.

\section{Yeast strain}

A xylose-fermenting strain, which we named CEN.PK $\mathrm{XXX}$, was engineered in two steps using targeted homologous recombination of linearised DNA fragments directly into the yeast chromosomes XVI and VIII of $S$. cerevisiae CEN.PK 122 MDS [35]. In the first step, the copy number of enzymes in the pentose phosphate pathway was increased by integration of an additional copy of the RPE1, TAL1 and RKI1 genes. The promoter of the 
TKL1 gene was also replaced with the glycolytic promoter of ENO1. The genetic construct was integrated into the $\mathrm{N}$-terminal coding region of the TKL1 gene in chromosome XVI to replace the native TKL1 promoter. The TKL1 coding sequence was left intact, and the RPE1, TAL1 and RKI1 genes were integrated upstream of the TKL1 gene. The integration event was selected for by using the resistance gene SMR1 (a mutant ILV2) and plating the transformed cells onto minimal medium agar plates with $50 \mu \mathrm{g} / \mathrm{ml}$ sulfometuron-methyl (Supelco, Bellefonte, PA, USA). In the second transformation, genes active in xylose metabolism were integrated: $X Y L 1$ and $X Y L 2$ from S. stipitis, and XKS1 from S. cerevisiae. The synthetic codon-optimised coding segments of $X Y L 1$, $X Y L 2$ and XKS1 were each fused upstream with new promoter segments from -500 to -1 of three glycolytic enzymes: the promoter of $P G K 1$ with $X Y L 1$, the promoter of TDH3 with XYL2 and the promoter of TPI1 with XKS1. The DNA segment containing the 'xylose genes' was flanked by segments of GRE3. The cells that had been transformed with the DNA fragment were transferred to a shake flask containing $20 \mathrm{~g} / \mathrm{l}$ xylose in $2 \times \mathrm{CBS}$ medium [36], and after 5 days, clear growth was seen. The strain was maintained on minimal medium agar plates with $20 \mathrm{~g} / \mathrm{l}$ D-xylose (Fisher Scientific, Leicestershire, England) as the only carbon source, and was used in all experiments.

\section{Media}

The growth medium used for the batch cultivations was a defined growth medium (DGM), as previously reported [37], with ergosterol and Tween 80 (both Sigma, Steinheim, Germany) added during anaerobic cultivations, and glucose, xylose or a combination of the two as carbon source.

The hydrolysate used was made from spruce chips at 18 bar pressure for 5 to 7 minutes at $\mathrm{pH} 2.0$ by addition of $\mathrm{SO}_{2}$, and kept refrigerated until use. Immediately prior to use, the $\mathrm{pH}$ was set to 5.5 with $10 \mathrm{M} \mathrm{NaOH}$. The medium was autoclaved and centrifuged to remove solid particles. The final concentrations in the medium used for anaerobic fermentations were: glucose $12.8 \pm$ $0.2 \mathrm{~g} / \mathrm{l}$, mannose $16.6 \pm 0.3 \mathrm{~g} / \mathrm{l}$, galactose $3.6 \pm 0.1 \mathrm{~g} / \mathrm{l}, \mathrm{xy}-$ lose $7.6 \pm 0.1 \mathrm{~g} / \mathrm{l}$, arabinose $2.4 \pm 0.0 \mathrm{~g} / \mathrm{l}$, acetic acid $3.1 \pm$ $0.0 \mathrm{~g} / \mathrm{l}$ and furfural $0.28 \pm 0.08 \mathrm{~g} / \mathrm{l}$, after addition of salts, vitamins and trace metals as in the defined media.

\section{Encapsulation procedure}

The capsules were prepared by the one-step, liquid droplet-forming method as described in [15]. In short, cells were grown in $100 \mathrm{ml} \mathrm{DGM} \mathrm{(40} \mathrm{g/l} \mathrm{glucose} \mathrm{and}$ $20 \mathrm{~g} / \mathrm{l}$ xylose) for 24 hours. Yeast was harvested from $50 \mathrm{ml}$ of medium at $\mathrm{OD}_{600}$ of approximately 4 by centrifugation at $3500 \times \mathrm{g}$ for 4 minutes, and resuspended in
$50 \mathrm{ml}$ of $1.3 \% \mathrm{w} / \mathrm{v}$ sterile $\mathrm{CaCl}_{2}$ (Scharlau, Sentmenat, Spain) solution containing $1.3 \% \mathrm{w} / \mathrm{v}$ carboxymethylcellulose (Aldrich, Steinheim, Germany) with an average molecular weight of $250 \mathrm{kDa}$ and degree of substitution of 0.9. Capsules were formed by dripping this solution through syringe needles into a stirred sterile solution of $0.6 \% \mathrm{w} / \mathrm{v}$ sodium alginate (catalogue number 71238; Sigma) and 0.1\% v/v Tween 20 (Sigma-Aldrich, Steinheim, Germany). After gelling for 10 minutes, the capsules were washed with sterile ultrapure water, and hardened in $1.3 \%$ $\mathrm{CaCl}_{2}$. The capsules were subsequently submerged for 24 hours in $0.2 \% \mathrm{w} / \mathrm{v}$ low molecular weight chitosan (catalogue number 448869; Aldrich) solution with $300 \mathrm{mM}$ $\mathrm{CaCl}_{2}$ in $0.040 \mathrm{M}$ acetate buffer, $\mathrm{pH} 4.5$.

\section{Cultivation and cell sampling}

Propagation of encapsulated cells in capsules of approximately $15 \mathrm{ml}$ was performed aerobically in $250 \mathrm{ml}$ cotton-plugged conical flasks filled with $100 \mathrm{ml}$ DGM containing $40 \mathrm{~g} / \mathrm{l}$ glucose and $20 \mathrm{~g} / \mathrm{l}$ xylose, which were incubated for 36 hours in a shaker bath (125 rpm) at $30^{\circ} \mathrm{C}$. The capsules were rinsed with sterile $0.9 \% \mathrm{NaCl}$ (Scharlau), and transferred to $100 \mathrm{ml}$ DGM containing $5 \mathrm{~g} / \mathrm{l}$ glucose and $40 \mathrm{~g} / \mathrm{l}$ xylose, then incubated for another 24 hours prior to the start of the anaerobic batch fermentations. We chose these concentrations of glucose and xylose to ensure rapid cell growth by inclusion of a high concentration of glucose in the first step, and to maintain efficient xylose metabolism by using a low glucose and a high xylose concentration in the second step.

Propagation of suspended yeast was started with aerobic cultivation for 24 hours in $100 \mathrm{ml} \mathrm{DGM} \mathrm{(40} \mathrm{g/l} \mathrm{glu-}$ cose and $20 \mathrm{~g} / \mathrm{l}$ xylose). Cells were harvested $(3500 \times \mathrm{g}$, 4 minutes) and resuspended to an $\mathrm{OD}_{600}$ of 3 in fresh medium of the same composition. After 36 hours, cells were again harvested and resuspended in $100 \mathrm{ml}$ fresh DGM (5 g/l glucose and $40 \mathrm{~g} / \mathrm{l}$ xylose) to an $\mathrm{OD}_{600}$ of 7.2 , and cultured for another 24 hours of aerobic propagation. The residual sugar concentrations at the end of each propagation culture were similar. Hence, the propagation steps for the encapsulated and the suspended cells were as similar as practically possible.

Anaerobic batch cultivations were performed in conical flasks, equipped with a rubber stopper fitted with stainless steel capillaries for sample removal and a loop trap filled with sterile water to permit the produced $\mathrm{CO}_{2}$ to leave the flasks. Anaerobic encapsulated cultures were started by transferring 30 capsules to $120 \mathrm{ml}$ of media containing combinations of glucose ( 0 or $40 \mathrm{~g} / \mathrm{l})$, xylose ( 0 or $40 \mathrm{~g} / \mathrm{l})$ and furfural $(0,1$ or $2 \mathrm{~g} / \mathrm{l})$ (Sigma-Aldrich). This gave an initial cell concentration of $0.272 \pm 0.014 \mathrm{~g}$ dry cells/l of liquid volume, meaning an average of $1.1 \mathrm{mg}$ dry cells per capsule in the form of a visible pellet inside each capsule. Anaerobic cultivations of suspended cells 
were started at initial cell concentrations of $0.258 \pm 0.030 \mathrm{~g}$ dry cells/l.

\section{Analytical methods, statistics, yields and elemental balance calculations}

Metabolite concentrations were quantified by HPLC using an Aminex HPX-87H column (Bio-Rad, Hercules, CA, USA) at $60^{\circ} \mathrm{C}$ with $5 \mathrm{mM} \mathrm{H}_{2} \mathrm{SO}_{4}$ as eluent at a flow rate of $0.6 \mathrm{ml} / \mathrm{min}$. A refractive index detector was used for the detection and quantification of glucose, xylose, xylitol, acetic acid, glycerol and ethanol. For the hydrolysate medium an Aminex HPX-87P (Bio-Rad), operated at $85^{\circ} \mathrm{C}$ with $0.6 \mathrm{ml} / \mathrm{min}$ ultrapure water as eluent, was used to quantify glucose, xylose, arabinose, galactose and mannose with a refractive index detector.

The cell dry weight was measured in predried and preweighed glass tubes. Cells were separated by centrifugation, and washed once with ultrapure water before drying for approximately 24 hours at $105^{\circ} \mathrm{C}$. Cells from capsules were released by crushing the capsule, followed by extensive washing of the capsule debris with ultrapure water.

Yields of metabolites and biomass, as well as the carbon balance, were calculated from the determined concentrations at the end of the fermentations. The biomass composition, $\mathrm{CH}_{1.76} \mathrm{O}_{0.56} \mathrm{~N}_{0.17}$ [38], was used in the carbon balance calculations. Error intervals are given as \pm 1 standard deviation with $\mathrm{n}=3$, unless otherwise indicated.

\section{Abbreviations}

DGM: Defined growth medium; FEM: Finite element modelling; HMF: 5-hydroxymethylfurfural; HPLC: high performance liquid chromatography; OD: Optical density.

\section{Symbols}

$\beta$ : Efficiency factor $(-)$; $c$ : Concentration $(\mathrm{mM}) ; C_{j}^{R}$ : Rate response coefficient to entity $j(-)_{i} C_{j}^{\beta}$ : Efficiency response coefficient to entity $j(-) ; D$ :

Diffusivity $\left(\mathrm{m}^{2} / \mathrm{s}\right) ; D$ : Dilution rate (per h); $K_{i}$ : Inhibition constant $(\mathrm{mM}) ; K_{M}$ : Half saturation constant (mM); $\mathrm{n}$ : Number of repeated experiment; $R$ : Total rate of reaction in cell pellet calculated by surface integration $(\mathrm{mol} / \mathrm{m} / \mathrm{s}) ; v$ : Specific rate $(\mathrm{mM} / \mathrm{g} / \mathrm{h}) ; Y_{\text {si }}$ : Yield of compound $i$ on consumed sugar $(\mathrm{g} / \mathrm{g})$.

\section{Subscripts}

Ace: Acetate; c: Cell pellet; EtOH: Ethanol; f: Furfural; g: Glucose; Gly: Glycerol; h: 5-hydroxymethylfurfural; H: High affinity; L: Low affinity; $m$ : Capsule membrane; max: Maximum; P: Parameter; W: Water; X: Xylose.

\section{Competing interests}

The authors declare that they have no competing interests.

\section{Authors' contributions}

JOW contributed to the idea and experimental design of the study and the interpretation of results, carried out all fermentation experiments, and was the main author of the manuscript. NB designed and constructed CEN.PK $X X X$, and contributed to the writing of the manuscript. MJT contributed to the idea of the study and writing of the manuscript. CJF contributed to the idea and design of the study, created the final kinetic models and performed the simulations, and contributed to the interpretation of results and writing of the manuscript. All authors read and approved the final version of the manuscript.

\section{Acknowledgements}

We are very grateful to Joana Paula Da Costa Pereira and Gonçalo Carvalho Esteves for performing initial in silico simulation studies and to Aires Coelho for performing initial laboratory experiments. We thank Dr. Tomas Brandberg at SEKAB AB, Sweden, for providing the spruce hydrolysate. We gratefully acknowledge funding by the Swedish Research Council (grant no. 2009-4514) the Chalmers Energy Initiative (http://www.chalmers.se/en/areas-of-advance/ energy/cei) and the University of Borås.

\section{Author details}

${ }^{1}$ School of Engineering, University of Borås, 50190 Borås, Sweden. ${ }^{2}$ Chemical and Biological Engineering, Industrial biotechnology, Chalmers University of Technology, 41296 Göteborg, Sweden.

Received: 28 January 2014 Accepted: 19 June 2014 Published: 3 July 2014

\section{References}

1. Wyman CE: Ethanol from lignocellulosic biomass: technology, economics, and opportunities. Bioresour Technol 1994, 50:3-15.

2. Zaldivar J, Nielsen J, Olsson L: Fuel ethanol production from lignocellulose: a challenge for metabolic engineering and process integration. Appl Microbiol Biotechnol 2001, 56:17-34.

3. Van Zyl C, Prior BA, Kilian SG, Kock JLF: D-xylose utilization by Saccharomyces cerevisiae. J Gen Microbiol 1989, 135:2791-2798.

4. Laluce C, Schenberg ACG, Gallardo JCM, Coradello LFC, PombeiroSponchiado SR: Advances and developments in strategies to improve strains of Saccharomyces cerevisiae and processes to obtain the lignocellulosic ethanol-a review. Appl Biochem Biotechnol 2012, 166:1908-1926.

5. Kötter P, Ciriacy M: Xylose fermentation by Saccharomyces cerevisiae. Appl Microbiol Biotechnol 1993, 38:776-783.

6. Bertilsson M, Andersson J, Lidén G: Modeling simultaneous glucose and xylose uptake in Saccharomyces cerevisiae from kinetics and gene expression of sugar transporters. Bioproc Biosyst Eng 2008, 31:369-377.

7. Meinander NQ, Boels I, Hahn-Hägerdal B: Fermentation of xylose/ glucose mixtures by metabolically engineered Saccharomyces cerevisiae strains expressing $X Y L 1$ and $X Y L 2$ from Pichia stipitis with and without overexpression of TAL1. Bioresour Technol 1999, 68:79-87.

8. Hamacher T, Becker J, Gárdonyi M, Hahn-Hägerdal B, Boles E: Characterization of the xylose-transporting properties of yeast hexose transporters and their influence on xylose utilization. Microbiology 2002, 148:2783-2788.

9. Sedlak M, Ho NWY: Characterization of the effectiveness of hexose transporters for transporting xylose during glucose and xylose co-fermentation by a recombinant Saccharomyces yeast. Yeast 2004, 21:671-684

10. Westman JO, Ylitervo P, Franzén C, Taherzadeh MJ: Effects of encapsulation of microorganisms on product formation during microbial fermentations. Appl Microbiol Biotechnol 2012, 96:1441-1454.

11. Pérez-Bibbins B, de Souza OR, Torrado A, Aguilar-Uscanga MG, Domínguez $J M$ : Study of the potential of the air lift bioreactor for xylitol production in fed-batch cultures by Debaryomyces hansenii immobilized in alginate beads. Appl Microbiol Biotechnol 2014, 98:151-161.

12. Pérez-Bibbins B, Salgado JM, Torrado A, Aguilar-Uscanga MG, Domínguez JM: Culture parameters affecting xylitol production by Debaryomyces hansenii immobilized in alginate beads. Process Biochem 2013, 48:387-397.

13. Galazzo JL, Bailey JE: Growing Saccharomyces cerevisiae in calcium-alginate beads induces cell alterations which accelerate glucose conversion to ethanol. Biotechnol Bioeng 1990, 36:417-426.

14. Westman JO, Manikondu RB, Franzén CJ, Taherzadeh MJ: Encapsulation-induced stress helps Saccharomyces cerevisiae resist convertible lignocellulose derived inhibitors. Int J Mol Sci 2012, 13:11881-11894.

15. Westman JO, Taherzadeh MJ, Franzén CJ: Proteomic analysis of the increased stress tolerance of Saccharomyces cerevisiae encapsulated in liquid core alginate-chitosan capsules. PLoS One 2012, 7:e49335. 
16. Vicente AA, Dluhý M, Ferreira EC, Mota M, Teixeira JA: Mass transfer properties of glucose and $\mathrm{O}_{2}$ in Saccharomyces cerevisiae flocs. Biochem Eng J 1998, 2:35-43.

17. Lebeau T, Jouenne T, Junter G-A: Diffusion of sugars and alcohols through composite membrane structures immobilizing viable yeast cells. Enzyme Microb Tech 1998, 22:434-438.

18. Hannoun BJM, Stephanopoulos G: Diffusion coefficients of glucose and ethanol in cell-free and cell-occupied calcium alginate membranes. Biotechnol Bioeng 1986, 28:829-835.

19. Tanaka H, Matsumura M, Veliky IA: Diffusion characteristics of substrates in Ca-alginate gel beads. Biotechnol Bioeng 1984, 26:53-58.

20. Merchant FJA, Margaritis A, Wallace JB, Vardanis A: A novel technique for measuring solute diffusivities in entrapment matrices used in immobilization. Biotechnol Bioeng 1987, 30:936-945.

21. Talebnia F, Niklasson C, Taherzadeh MJ: Ethanol production from glucose and dilute-acid hydrolyzates by encapsulated S. cerevisiae. Biotechnol Bioeng 2005, 90:345-353.

22. Kim SR, Kwee NR, Kim H, Jin Y-S: Feasibility of xylose fermentation by engineered Saccharomyces cerevisiae overexpressing endogenous aldose reductase (GRE3), xylitol dehydrogenase (XYL2), and xylulokinase (XYL3) from Scheffersomyces stipitis. FEMS Yeast Res 2013, 13:312-321.

23. Jin Y-S, Ni H, Laplaza JM, Jeffries TW: Optimal growth and ethanol production from xylose by recombinant Saccharomyces cerevisiae require moderate d-Xylulokinase activity. Appl Environ Microbiol 2003, 69:495-503.

24. Sárvári Horváth I, Taherzadeh MJ, Niklasson C, Lidén G: Effects of furfural on anaerobic continuous cultivation of Saccharomyces cerevisiae. Biotechnol Bioeng 2001, 75:540-549.

25. Lee WJ, Kim MD, Ryu YW, Bisson L, Seo JH: Kinetic studies on glucose and xylose transport in Saccharomyces cerevisiae. Appl Microbiol Biotechnol 2002, 60:186-191.

26. Leandro MJ, Fonseca C, Gonçalves P: Hexose and pentose transport in ascomycetous yeasts: an overview. FEMS Yeast Res 2009, 9:511-525.

27. Mogi N, Sugai E, Fuse $Y$, Funazukuri T: Infinite dilution binary diffusion coefficients for six sugars at $0.1 \mathrm{MPa}$ and temperatures from (273.2 to 353.2) K. J Chem Eng Data 2006, 52:40-43.

28. Yaws CL: Yaws' Handbook of Thermodynamic and Physical Properties of Chemical Compounds. Knovel: 2003 [http://app.knovel.com/hotlink/toc/id: kPYHTPPCC4/yaws-handbook-thermodynamic]

29. Wilke $C R$, Chang P: Correlation of diffusion coefficients in dilute solutions. AlChE J 1955, 1:264-270.

30. Cheong SH, Park JK, Kim BS, Chang HN: Microencapsulation of yeast cells in the calcium alginate membrane. Biotechnol Tech 1993, 7:879-884.

31. Ylitervo P, Franzén CJ, Taherzadeh M: Impact of furfural on rapid ethanol production using a membrane bioreactor. Energies 2013, 6:1604-1617.

32. Jordan DB, Braker JD, Bowman MJ, Vermillion KE, Moon J, Liu ZL: Kinetic mechanism of an aldehyde reductase of Saccharomyces cerevisiae that relieves toxicity of furfural and 5-hydroxymethylfurfural. Biochim Biophys Acta (BBA) 2011, 1814:1686-1694.

33. Kostesha NV, Almeida JRM, Heiskanen AR, Gorwa-Grauslund MF Hahn-Hägerdal B, Emnéus J: Electrochemical probing of in vivo 5-hydroxymethyl furfural reduction in Saccharomyces cerevisiae. Anal Chem 2009, 81:9896-9901.

34. Liu ZL, Moon J: A novel NADPH-dependent aldehyde reductase gene from Saccharomyces cerevisiae NRRL Y-12632 involved in the detoxification of aldehyde inhibitors derived from lignocellulosic biomass conversion. Gene 2009, 446:1-10.

35. Gietz RD, Woods R: Yeast transformation by the LiAc/SS carrier DNA/PEG method. In Methods in Molecular Biology, Volume 313 Yeast Protocol. Edited by Wei X. Totowa: Humana Press; 2006:107-120.

36. Verduyn C, Postma E, Scheffers WA, Van Dijken JP: Effect of benzoic acid on metabolic fluxes in yeasts: a continuous-culture study on the regulation of respiration and alcoholic fermentation. Yeast 1992, 8:501-517.
37. Taherzadeh MJ, Lidén G, Gustafsson L, Niklasson C: The effects of pantothenate deficiency and acetate addition on anaerobic batch fermentation of glucose by Saccharomyces cerevisiae. Appl Microbiol Biotechnol 1996, 46:176-182.

38. Verduyn C, Postma E, Scheffers WA, van Dijken JP: Physiology of Saccharomyces cerevisiae in anaerobic glucose-limited chemostat cultures. J Gen Microbiol 1990, 136:395-403.

doi:10.1186/1754-6834-7-102

Cite this article as: Westman et al.: Improved sugar co-utilisation by encapsulation of a recombinant Saccharomyces cerevisiae strain in alginate-chitosan capsules. Biotechnology for Biofuels 2014 7:102.

\section{Submit your next manuscript to BioMed Central and take full advantage of:}

- Convenient online submission

- Thorough peer review

- No space constraints or color figure charges

- Immediate publication on acceptance

- Inclusion in PubMed, CAS, Scopus and Google Scholar

- Research which is freely available for redistribution

Submit your manuscript at www.biomedcentral.com/submit
C Biomed Central 